\title{
A sociologia frente aos riscos dos livros didáticos de ciências econômicas e sociais'
}

Philippe Vitale

\section{Resumo}

Inspirado pela sociologia do curriculum anglo-saxônica, este artigo busca esclarecer a recontextualização da sociologia na seção Sciences Économiques et Sociales (SES), através de uma análise de seus livros didáticos. A análise se apoia no conjunto de obras da segunda série e, particularmente, sobre os capítulos que tratam da sociologia. Esse exame conduz in fine a desprender quatro formas de recontextualização que convidam a uma reflexão epistemológica, didática e pedagógica sobre o ensino de Sociologia em SES.

Palavras-chave: SES. Ensino de Sociologia. Curriculum. Livro didático. Recontextualização.

\section{Introdução3}

Inaugurado por Émile Durkheim na Évolution pédagogique en France (1938), o exame dos programas e dos conteúdos do ensino suscitou pouco interesse entre a maior parte dos sociólogos franceses (DURKHEIM, 1938; ISAMBERT-JAMATI, 1990; ROPÉ; BUCHETON; LELOCH, 1994), enquanto que nos países de língua inglesa, ele deu lugar a uma forte tradiçáo de pesquisa que designamos geralmente sob o termo de "sociologia do currículo"4.

I Este artigo foi publicado originalmente sob o título "La sociologie au risque des manuels: l'exemple des manuels en classe de seconde Sciences Economiques et Sociales", na Revue française de pédagogie, n' I34, INRP, 200 I, http://rfp.reuues.org/persee-281578. (VITALE, 200I). Agradecemos ao autor Philippe Vitale, e aos editores da revista, em especial a Jean-Yves Rochex (Editor chefe) e Anne Farys (Secretária de redação) pela graciosa autorização e a confiança na tradução e publicação do texto. Tradução de Juarez Lopes de Carvalho Filho, professor e pesquisador do Departamento de Sociologia e Antropologia e membro do corpo docente do Programa de Pós-Graduação em Ciências Sociais, da Universidade Federal do Maranhão, São Luis/Brasil.

2 Philippe Vitale é Maître de conférences en sociologie no Pole Humanités Sciences Historiques et Sociales a Aix-Marseilles Université.

3 Este texto é fruto de um trabalho realizado em 1998-1999 pelo Laboratoire Méditerranéen de Sociologie (LAMES), com participação de Nicole Romognino, Pierrette Vergès, Pierre Vergès e Philippe Vitale. Ver Vitale, 1999.

4 Para uma apresentação da história e das contribuições originais da sociologia "du curriculum", ver as obras de Jean-Claude Forquin (1989): École et culture, Bruxelles, De Boeck Université, e (1997) Les sociologues de 
A análise dos livros didáticos ${ }^{5}$ de segunda série ${ }^{6}$ de "Sciences Économiques et Sociales" $(\mathrm{SES})^{7}$ se inscreve na perspectiva geral feita em outre-Manche sobre a relação entre o curriculum formal, ou seja, os conteúdos que são prescritos oficialmente pelas autoridades, e o curriculum real-dito de outra maneira, os saberes realmente transmitidos na prática. Os livros didáticos se encontram na interface de dois tipos de "curricula". Diferentemente do que ocorre nos programas, esses suportes pedagógicos não são estabelecidos pelo Ministério de Educação nacional. Eles são essencialmente redigidos por professores de economia e as editoras não têm necessidade de obter qualquer aprovação das autoridades para publicá-los. Os autores são obrigados, em princípio, a seguir o curriculum formal proposto pela Educação Nacional; mas, em razáo do caráter às vezes vago e alusivo de seu conteúdo, eles operam variaçóes que obedecem às lógicas de produção complexas e plurais: lógica mercadológica ligada à edição, lógica pedagógica ligada à finalidade desses livros, lógica de autores em concorrência no mercado, lógicas científicas que se escrevem no plural, pois as instruçôes ministeriais e a ausência de normatividade em ciências sociais deixam uma "margem de manobra" importante aos autores. Além disso, os livros didáticos não não dependem do curriculum real. Eles constituem um suporte pedagógico para o aluno e para o professor que pode escolher se reportar, ao longo da disciplina, a outros suportes (fotocópias de obras, recortes de jornais, revistas especializadas etc.).

Os livros didáticos se apresentam, nesse sentido, como campo de investigação privilegiado para o sociólogo. Eles são ferramentas de recontextualização pedagógica do saber acadêmico que é preciso levar a sério por qualquer análise de uma disciplina escolar. O conceito de recontextualização, que

l'éducation américains et britanniques, Bruxelles, da editora De Boeck-I.N.R.P. Precisamos aqui que o termo "curriculum" em inglês designa, ao mesmo tempo, um programa, saberes escolares, um percurso educacional e mais amplamente "[...] uma perspectiva global dos fenômenos educativos, uma maneira de pensar a educação que consiste em privilegiar a questão dos conteúdos e a maneira como esses conteúdos se organizam nos cursus" (FORQUIN, 1989, p. 22).

5 No original, usa-se a expressão "manuels scolaires"; porém, preferimos traduzir por "liuros didáticos", por ser a expressão recorrente nos estudos sobre o Ensino de sociologia na Educação Básica no Brasil (Nota do Tradutor).

6 Corresponde, no Brasil, ao primeiro ano do Ensino Médio (Nota do Tradutor).

7 Esta é a nomenclatura, na França, que contempla o ensino de sociologia na educação secundária que traduzimos por "Ciências Econômicas e Sociais", doravante CES. ( Nota do Tradutor.).

8 Em Latim no texto original. Curricula é o plural de curriculum (equivalente de currículo, em Português). 
tomamos emprestado de Basil Bernstein (BERNSTEIN 1996a; 1996b) ${ }^{9}$ designa o processo pelo qual os livros "[...] se apropriam, relocalizam, recentram e religam, seletivamente entre eles" (1996a p. 47), os saberes acadêmicos. Os livros didáticos criam in fine um discurso pedagógico específico que não pode ser assimilado aos discursos que ele transmite. Assim, trata-se menos de um discurso do que de um "princípio de engendramento" (1996a) da linguagem acadêmica. Isto é, sobretudo, o caso das CES que constituem uma disciplina híbrida em busca de identidade. Uma simples recensão dos títulos dos primeiros capítulos ${ }^{10}$ dos livros revela a variabilidade dos "curricula": "A família" (Belin); "O objeto das ciências econômicas e sociais" (Bordas); "Introdução" (Bréal), que conjuga dois capítulos "Olhares cruzados sobre as férias e a escassez", "A força dos fortes: uma novela de Jack London" (La Découverte); "Compreender a economia e a sociedade" (Hachette); "Introdução" (Hatier), composta pelos seguintes dossiês: "A publicidade, um fenômeno econômico e social", "Necessidade e escassez, uma perspectiva econômica e social", "Como vivemos: abundância ou escassez?" (Nathan)".

Podemos distinguir várias lógicas que são próximas e complicadas na realização de um livro de CES, mesmo que cada uma dessas lógicas seja ela mesma complexa, à medida que há diferenças entre as soluçóes que são apresentadas a cada um dos problemas, aos quais essas diversas lógicas respondem. A primeira dessas lógicas concerne o conhecimento sociológico; todavia, sua recontextualização não é simples, pois ele remete a uma diversidade de soluçóes. De uma parte, pelo fato de existirem vários paradigmas em sociologia e os autores citados poderem remeter à hipótese de um recorte disciplinar de um campo científico ou, ao contrário, à ideia de uma ciência específica que constituiria o conjunto das Ciências Humanas e Sociais (hipóteses recorrente desde a criaçáa das CES). De outra parte, o universo metodológico, as formas de observação são, também, heterogêneas, oscilando entre métodos quantitativos e métodos qualitativos, o que complica tanto mais a heterogeneidade dessa lógica de conhecimento.

9 Tentei, por outro lado, operacionalizar o conceito de "recontextualização" na minha tese de doutorado (1999) L'enseignement de la sociologie: vers une étude comparative des curricula européens, Université de Provence.

10 Para alguns liuros, os "temas" e as "partes".

II Entre parênteses, estão as respectivas editoras que publicaram os livros didáticos aqui analisados (Nota do Tradutor). 
Uma segunda lógica refere-se à validade histórica da ciência, dando lugar, de uma parte, a um debate entre a sociologia da ciência e epistemologia; de outra, a tomadas de posição diferentes no plano pedagógico. Mesmo o debate sendo interno ao campo científico, ele não tem menos efeito sobre o outro campo, a saber, o da transmissão do conhecimento científico: deve-se transmitir pedagogicamente o conhecimento estabelecido ou deve-se transmitir todo um desenvolvimento do espírito crítico em relação a esse conhecimento? Diremos rapidamente aqui que a sociologia, mais que qualquer outra ciência, conhece e reconhece esse problema, pois sua história náo é a do desenvolvimento histórico de seus paradigmas, mas uma história esfacelada desde sempre pelo "politeísmo de valores", para retomar uma expressão de Max Weber.

Uma terceira lógica diz respeito à funçáo do livro didático como objeto pedagógico e, por conseguinte, do trabalho pedagógico de uma disciplina científica, daquilo que nomeamos comumente de "vulgarização científica". Vários problemas se enredam nessa lógica e suas soluçôes são variáveis. Um dos problemas principais consiste na definiçáo dos objetivos relativos ao ensino das CES: busca-se, através do livro didático, transmitir um espírito científico ou busca-se, através da transmissão dos conhecimentos, veicular um espírito humanista, cívico? Dito de outra maneira, busca-se instruir ou educar os alunos?

Nosso objetivo, neste espaço limitado, não tem por ambição resolver os diferentes problemas que podemos colocar ao ensino de sociologia no âmbito das CES; mas, antes de tudo, demonstrar como essa disciplina é recontextualizada nos livros. Ou seja, interessamo-nos aqui neste artigo, unicamente pelos conteúdos que podem estar referidos à sociologia. Começaremos por efetuar uma leitura do capítulo consagrado à família; tema que constitui o elemento mais sociológico do curriculum formal da segunda série em CES. Esse exame nos levará a apresentar quatro formas de recontextualização da sociologia em CES, as quais ilustraremos por meio de exemplos extraídos dos livros didáticos analisados. Terminaremos com uma discussão acerca dos problemas epistemológicos, didáticos e pedagógicos, suscitados por essa recontextualização. 


\section{A família nos livros didáticos em CES na segunda série}

\section{I Elementos de recensão estatística dos documentos utilizados nos capítulos sobre o estudo da família nos livros de CES}

Voltemos, antes de tudo, à escolha deste exemplo. O tema da família, como já mencionamos, é o mais susceptível de ser tratado de maneira sociológica. A família é uma realidade cotidiana; os alunos são obrigados a abrir mão da sua evidência para construir um objeto nocional. Essa escolha se justifica pela pluralidade das linguagens científicas e dos modos de observação que se oferecem aos autores dos livros para apresentar a família aos alunos. A perspectiva desse tema articula, entáo, várias disciplinas, visto que pode ser abordado de maneira demográfica e sociológica através das transformaçóes modernas de família, dos modos de socialização e reprodução social. As formas e a organização familiares foram, também, estudadas pelos antropólogos que trabalham sobre o parentesco. O papel econômico dos ménages pode conduzir, enfim, à descrição da família na produção e no consumo.

$\mathrm{Na}$ nossa recensão, buscamos, de uma parte, identificar os diferentes tipos de documentos relativos ao tema, e, de outra, observar sua distribuição segundo os diferentes livros didáticos. Assim, examinamos cada documento, segundo: o título do documento, a fonte, o ou os autores, o editor, o ano de edição, o número de vezes que ele é citado.

Para o conjunto dos livros didáticos, contamos 295 documentos - e 203 são de referências. Chama atenção, na tabela a seguir, a diferença do número de documentos utilizados, segundo o livro:

Tabela I - Distribuição dos livros didáticos, documentos e referências por editoras ${ }^{12}$

\begin{tabular}{lcccccccc}
\hline $\begin{array}{l}\text { Livros } \\
\text { didáticos/ } \\
\text { Editoras }\end{array}$ & Découverte & Bréal & Bordas & Nathan & Hachette & Belin & Hatier & Total \\
\hline Documentos & 61 & 43 & 41 & 39 & 38 & 37 & 36 & 295 \\
\hline Referências & 41 & 27 & 27 & 26 & 30 & 24 & 28 & 203 \\
\hline
\end{tabular}

Fonte: Elaborada pelo autor.

12 No texto original não existe título para esta tabela. Optamos pelo seguinte título acima (Nota do Tradutor) 


\subsection{As fontes}

Buscamos identificar as fontes, embora algumas vezes isso não tenha sido possível, uma vez que certas revistas e alguns artigos de imprensa eram desprovidos de referências. Duas fontes principais são utilizadas: as estatísticas e as obras. Nos capítulos consagrados à família, as fontes estatísticas são citadas abundantemente ( 44 documentos) e apresentam uma diversidade desigual: dados sociais (20), Tabela da economia francesa - TEF (16), Recenciamento geral da população - R.G.P. (5), Anuário estatístico da França (3). É preciso acrescentar a essa lista as revistas estatísticas (28), que se constituem dos seguintes documentos: INSEE ${ }^{13}$ primeiro (17), O estado da França (3), Economia e estatística (3); INSEE resultado (2); INSEE estudos sociais (1), INSEE problemas políticos e sociais (1), Infor stats $\mathrm{n}^{\circ} 5$ Ministério da Justiça (1). Percebemos que há dois tipos de documentos: dados sociais e INSEE primeiro. As revistas especializadas (sociológicas, econômicas e demográficas) são, também, utilizadas (40 citaçóes), havendo uma prioridade para a revista econômica Écoflash e para a Sciences Humaines ${ }^{14}$. Os empréstimos às revistas generalistas (12) são mais dispersas, enquanto que o "Le Monde" é, em matéria de impressa cotidiana, a fonte privilegiada ${ }^{15}$. Por fim, os dicionários utilizados são principalmente os editados pelas seguintes editoras: Armand Colin, Hatier e Larousse.

Em seguida, operamos uma classificação dos autores de obras "e somente de obras", ou seja, excluímos os artigos, as enquetes, as fontes estatísticas, os dicionários. Sobre o efetivo total dos 295 documentos, 106 representam extratos de obras que podemos qualificar de "referência" sobre o tema. Os dois terços dos autores dessas obras são de sociólogos com dominantes em certos livros: Roussel e Segalen no livro editado por Bordas (9 documentos em 10), De Singly na La Découverte (8 em 17), Le Gall e Martin em Nathan (4 em 7).

13 Institut national de statistique et études économiques (Instituto Nacional de Estatistica e Estudos Econômicos). (Nota do Tradutor.)

14 Revues sociologiques (18): Sciences humaines (II), L'année sociologique (3), Actes de la recherche en sciences sociales (I), Recherches sociologiques (I). Revue de sciences sociales de la France de l'Est (2); Revue économiques (18): Ecoflash (II), Alternatives économiques (7); Revues démographiques (4) Population (2), Populations et sociétés (2).

15 Revues généralistes (12): Politis (2), Communications (2), Le Monde de l'Education (2), Le Point (2), Projet (I), Cahiers français (I), Panoramiques (I), Esprit (I); Presse quotidienne (I3): Le Monde (8), Liberation (3), La Croix (I), Le Parisien (I). 
Em outros livros, as referências sociológicas são várias, tendo no topo da lista: De Singly, Segalen, Roussel, Bourdieu, Kaufmann, Le Gall e Martin. O último terço se reparte entre os historiadores, em número de 12, dos quais 6 são publicados em Hachette; os antropólogos totalizam 13, dos quais 5 também são publicados em Hachette; e 9 (do total de 10) dos literários são publicados na Le Découverte, na coleção Manuels. Se o INSEE se impóe como o grande provedor de informaçóes, náo existe um autor privilegiado nos livros didáticos. A lógica da seleção é, mais uma vez, complexa e plural. A importância das estatísticas não deve ocultar o apelo aos dados qualitativos, em particular os discursos. E a justaposição das estatísticas e das entrevistas, que funcionam como recursos essenciais, não é evidente. Ela coloca a questão do estatuto acordado à "parole des gens", na análise sociológica. A "parole des gens" pode, em efeito, tomar formas diversas, observada in situ, ou a partir de protocolos de enquetes, de documentos ou arquivos históricos da literatura, e dar lugar a escolhas teóricas e metodológicas diferentes. Nos livros, em nenhum momento se coloca a questão da importância dessas diferentes fontes e de suas formas de interpretação. Quando existe um prefácio, trata-se, mais frequentemente, de esquemas didáticos complexos que desenham uma rede de diferentes componentes de livros didáticos e que, supostamente, devem fornecer uma chave de leitura aos alunos.

Enfim, efetuamos uma classificação dos autores de outros documentos para ver se as tendências observadas se prolongavam. Encontramos uma dominante da estatística e da sociologia. Sobre o corpus dos 285 documentos, 83 são assinados pelo INSEE ou $\mathrm{INED}^{16}$, 79 são dedicados aos sociólogos. Do mesmo modo que a história, a antropologia representa pequeno efetivo (22); e a economia é, por sua vez, quase ausente neste capítulo (3 documentos).

\section{As formas de recontextualização da sociologia da família}

Sobre a base dessa descrição numérica, podemos observar nos livros de CES quatro formas de recontextualização da sociologia: a sociologia em oposição ao senso comum; a experiência exótica ou o apelo à alteridade; o uso ilustrativo da estatística e o convite à literatura.

16 Institut national d'études démographiques (Instituto Nacional de Estudos Demográficos) (Nota do Tradutor). 


\section{I A sociologia em oposição ao senso comum}

Quaisquer que sejam os sociólogos mencionados nos livros, seus escritos são sempre apresentados como exemplos de ruptura com a leitura espontânea do real. Seguindo a perspectiva objetivista bachelardiana do Métier de sociologue (BOURDIEU; CHAMBOREDON; PASSERON, 1968), os autores dos livros convocam a sociologia a cada vez que se trata de mostrar aos alunos a necessidade de problematizar as ilusóes e os preconceitos do senso comum. Desse modo, são citados, sucessivamente, extratos de texto, entrevistas, recortes de jornais, tabelas estatísticas, sem nenhuma apresentação dos autores, não ocorrendo qualquer tipo de explicação sobre as razóes de suas seleçóes. O tema do casamento constitui, assim, um bom exemplo de tradução das categorias profanas em categorias acadêmicas. O livro da editora Hatier ilustra, de maneira clara, esse caráter misto. No capítulo consagrado à família, a questão da "formação do casal" é abordada (HATIER, S/d p. 28-30) através de cinco documentos: o primeiro texto de Ghasarian, intitulado "Endogomia ou exogamia"; um segundo de L. Roussel "como se escolhe um cônjuge?”; um extrato do romance "Une vie" de G. de Maupassant renomado pelos autores "um casamento arranjado"; um quadro de M. Bozon sobre o lugar de encontro dos cônjuges"; e um outro oriundo da enquete empregada pelo INSEE sob o título "qui se ressemble s’assemble"?17 Esses textos são assim justapostos, sem nenhum comentário dos autores, dos textos antropológicos, sociológicos, literários e dados estatísticos. Esses documentos - diferentes por sua data de produção, sua fonte e suas referências teóricas - são considerados, pelos autores, como equivalentes sob o plano cognitivo: eles sáo presumidos a oferecer aos alunos os resultados de um processo de conhecimento sociológico e têm, desse fato, o mesmo estatuto epistemológico. No entanto, esse estatuto não é evidente nos livros, pois esses textos são associados a outros documentos de natureza diferente. Uma confusão pode, então, se operar no espírito dos alunos entre categorias acadêmicas e profanas.

\subsection{A experiência exótica ou o apelo à alteridade}

Nos livros didáticos, a ruptura com os estereótipos é, por outro lado, ilustrada pelos exemplos oriundos da etnologia e da antropologia. O conteúdo

17 Expressão equivalente ao adágio português: "Pássaros da mesma plumagem, voam juntos" 
"exótico", em termos de distância ou de olhar distanciado, tem por objetivo esclarecer o etnocentrismo que subentende as representaçóes ocidentais do "Outro". Os alunos são, então, convidados a "pensar a diferença", a interrogar suas próprias disposiçóes de espírito descritas como "culturalmente determinadas". O tema da família ilustra bem essa dialética entre universalismo e relativismo. A recusa do esquema evolucionista, a desnaturalizaçáo das formas e das relaçóes familiares ocidentais é associada a uma leitura sociológica daquilo que nos é apresentado como crise da família contemporânea. Em torno do inventário dos novos modelos familiares (recomposto etc.), articula-se uma descrição demográfica da atualidade da crise e uma análise econômica e sociológica. No entanto, à diferença da démarche precedente, os autores não interrogam o sentido familiar, suas funçóes e seus fundamentos. Salta-se, assim, do relativismo cultural - expresso pelo lugar dos textos etnológicos na sequência dos capítulos - a um determinismo sociológico. As novas formas familiares são o resultado das condiçóes econômicas e sociais. A associação desse relativismo cultural a outras explicaçóes pode ser ilustrada pela sucessão dos parágrafos nos livros didáticos. Desse modo, na edição Hatier, a formação dos casais faz referência à etnologia, em seguida, a um relato e, enfim, à sociologia. Mais adiante, a história vem trazer sua contribuição. No entanto, se nos prendermos aos títulos do capítulo sobre a família, essa distribuição, entre as diferentes disciplinas, aparece claramente.

A formação dos casais.

$2-2-A-14$

Endogamia ou exogamia.

$2-3-\mathrm{A}-15$

Um casamento "conciliado".

$2-3-A-16$

O lugar de encontro dos casais.

$2-3-A-17$

Como se escolhe o cônjuge?

$2-3-A-18$

"Qui se ressemble s'assemble".

$2-3-B$

O lugar das crianças no seio da família.

18 A numeração e os títulos dos parágrafos foram conservados (Nota do autor). 
2-3-B-19

2-3-B-20

$2-3-B-21$

$2-4$

$\mathrm{Na}$ Idade Média, o sentimento de infância não existia. Uma árvore protegida.

Laço biológico ou laço afetivo?

Tema: As solidariedades entre geraçóes.

O tema das diversidades das formas familiares pode, da mesma forma, ser visto através da história (“A família nuclear: uma realidade antiga”) e da etnologia ("a diversidade das relaçóes de filiação, a diversidade das formas matrimoniais"). A sucessão de referências disciplinares é certamente desconcertante. Às vezes, é preciso acrescentar a isso certa ausência da lógica na sucessão dos parágrafos: voltamos à mesma noção em vários parágrafos distantes e nos contextos disciplinares diferentes. Desse modo, em outro livro (Bréal), as razôes da homogamia são abordadas pela sociologia ("Onde encontrar seu cônjuge"?) e a importância da homogamia pela etnologia ("A escolha do cônjuge nos Arapesh").

\subsection{O uso ilustrativo da estatística}

A visão expressa pelos títulos é argumentada por tabelas e curvas estatísticas. O título "A família em mutação profunda" é, por exemplo, ilustrado no livro Bordas pelo conjunto de tabelas tendo por eixo o tempo (de 1945 até nossos dias). Temos aqui um assunto de démarche indutiva, visto que o aluno é presumido construir seu próprio saber.

Isso deve ser colocado em relação com a importância das fontes INSEE e INED. No caso do livro Bordas, essa démarche parece associada a uma tomada de posição pelos autores: o primeiro título fala da "Nupcialidade em crise". Em efeito, a démarche é muito mais neutra; os títulos das tabelas e dos gráficos são, sobretudo, constataçóes: "Evolução do número dos casamentos", "O celibato se desenvolve", "As formas da família se diversificam". A apresentação das estatísticas e das questóes que são associadas visam a desprender três tempos de reflexão:

- Identificação dos fatos: "Em 1990...\% das famílias com crianças são famílias monoparentais, contra...\% em 1968. 
- Uma démarche explicativa que não é obrigatoriamente causal: "como explicar o que você constata?" (BORDAS, S/d, p. 35) é, então, a questão que vem de maneira quase sistemática.

- Uma pesquisa de causalidade: "Qual era a principal causa da existência da família monoparental?” (Ibid., S/d, p. 35-39).

Esse terceiro tempo nem sempre é investigado. Essa démarche indutiva é talvez, também, outra forma de relativismo cultural transportada na nossa sociedade atual; relativismo fundado sobre as diferenças entre geraçôes e entre grupos sociais. Essa forma conduz a uma acumulação de dados paralelos: "casa-se menos e mais tarde"; "O divórcio e o celibato estão em amplo crescimento"; "Queda da natalidade e da fecundidade" (Ibid., p. 36-38)... Demanda-se, assim, implicitamente, ao professor e ao aluno, selecionar e fazer sua escolha no conjunto dessas informaçóes.

\subsection{Convite à literatura}

Vimos anteriormente que os documentos literários eram mais raros nos livros didáticos. Podemos, no entanto, interrogar sobre o uso que é reservado a esses documentos, uma vez que a relação entre ciências sociais e literatura é uma das questóes epistemológicas mais controversas. Distinguimos, nos referidos livros, três gêneros literários que ilustram ou que se substituem segundo os casos de conhecimento sociológico: a ficção, o romance realista e o autobiográfico. Podemos antecipar que, nesses usos, existe uma vontade pedagógica dos autores: o apelo à diversidade das fontes para iniciar os alunos na démarche objetivante. Podemos, também, ver nesse convite à literatura e, notadamente, no caso da biografia e da autobiografia, a dificuldade de os autores encontrarem textos sociológicos que tratam do indivíduo, do sujeito. A singularidade é raramente abordada pela sociologia. O apelo à memória "individual" dos literatos (Por exemplo: A. Ernaux no livro La Découverte) pode ser, então, um meio heurístico para ilustrar uma experiência singular inscrita nos tempos sociais. Mas a pedagogia pode passar, ainda, pela explicitação da diferença entre a literatura e as ciências sociais. No entanto, não é isso que os autores propóem: as palavras e as coisas se confundem; a literatura representa o conhecimento sociológico. Acrescenta-se, ao risco de confusão dos alunos-leitores, uma desnaturalizaçáo da forma de conhecimento literário, enquanto que esse conhecimento poderia mostrar a ausência de ruptura entre conhecimento científico e conhecimento literário, sublinhando, ao mesmo tempo, que seus 
procedimentos são, também, diferentes, não servindo nem aos mesmos objetivos, nem às mesmas relaçóes ao mundo natural e social.

A primeira parte do livro da La Découverte (S/d p. 9-31) constitui um exemplo importante de uso da literatura como recurso pedagógico. A questáo que podemos propor, a partir da leitura das primeiras páginas, é a seguinte: por que os autores escolheram uma novela de Jack London, "La force des forts" (CHARLOT, 1997) e expuseram-na, no lugar, em vez de empregarem a linguagem científica propriamente dita? A novela de J. London começa por um paratexto de Lip-King: "As parábolas não mentem, mas os mentirosos as utilizam". Parece que esse paratexto, enfatiza de maneira justa como a novela pode ser lida: como uma parábola. O que é uma parábola? É um convite a exercer uma comparaçáo, mas o objeto comparado é escondido e permanece enigmático. Nesse sentido, a novela de London carece efetivamente, para ser entendida, que o leitor busque o enigma e não a solução do enigma. Porém, a relação epistémico (CHARLOT, 1997) ao saber consiste justamente em saber construir enigmas, problematizar permanentemente o real, qualquer que seja o conhecimento e o saber que os alunos possuem. Trata-se de investigar uma realidade oculta; mas, para isso, implica perguntar o que é, o que se vê e o que se conhece como enigma a resolver. A parábola se constitui como relaçáo à linguagem específica que é necessário construir. Ao mesmo tempo, a parábola suscita uma "tomada de leitura", da mesma forma como se fala de "tomada de consciência”. Nesse livro, a virtude pedagógica da ficção de Jack London se inscreve na mistura de gêneros.

\section{A escolha do cônjuge: as diferentes recontextualizações}

Os livros didáticos expressam as variações na recontextualização da sociologia. $\mathrm{O}$ mesmo tema pode ser apresentado de maneiras muito diferentes segundo o livro. Tomemos, por exemplo, o tema "escolha do cônjuge" abordado no capítulo sobre a família. Encontramos dois modos de contextualização: o relativismo cultural e o determinismo social.

\section{I O relativismo cultural}

O relativismo cultural é ilustrado particularmente pelos livros Bréal e Bordas. A escolha do cônjuge é abordada principalmente pelo ângulo antropológico e etnológico. No livro publicado pela editora Bréal, os autores 
paradoxalmente selecionaram um único extrato de texto assinado pelo sociólogo A. Girard que trata do parentesco, da aliança (termos que são por outro lado sublinhados no livro), para abordar a homogamia. O paratexto reforça esse convite antropológico suposto permitir aos alunos tomar distância objetivante relativa à nossa própria sociedade: "A liberdade da escolha do cônjuge não é incondicional. Assim, os casais se formam segundo uma homogamia social que persiste com o tempo, mesmo quando os costumes se liberam" (BRÉAL, S/d, p. 51). Bordas distingue, por sua vez, a exogamia e a endogamia da heterogamia, e a homogamia sobre a base de três documentos. Subintitulados, respectivamente, La famille émergence de la règle de l'exogamie et Autrefois dans les Pyrénées, de J.-L. Flandrin, e o extrato de La famille incertaine, de L. Roussel, propóem aos alunos uma leitura etnológica daquilo que é chamado pelos autores de manual de "regras de aliança". A endogamia e a homogamia são assim ilustradas pelas estratégias matrimoniais dos "jovens rapazes das aldeias de outrora". Empregamos voluntariamente o termo "outrora", citado no título, pois nenhuma informação histórica nos é dada nos textos. O último documento apresenta, enfim, a atualidade das tendências colocada em destaque nas descriçóes etnográficas.

\subsection{0 determinismo social}

O determinismo social aparece no conjunto dos manuais. A literatura sociológica é convocada desde que se trate, para retomar o objetivo declarado no paratexto do livro Bréal, de "observar os determinismos sociais". M. Bonzon e F. de Singly são os autores mais citados para objetivar o fenômeno de reprodução social. Extratos de entrevistas sobre o "gosto", "o acaso" na escolha do cônjuge, são acompanhados de textos, de tabelas e de esquemas para mostrar aos alunos-leitores a importância das características sociais dos indivíduos. Com o intuito de ilustrar esse determinismo social, citamos o exemplo da introdução sobre a escolha do cônjuge em Bordas:

Antes de formar uma família, é necessário escolher um cônjuge. Essa escolha é uma questão somente individual que interessa apenas as duas pessoas concernentes? Ou engaja outras pessoas ou grupos sociais? Nas sociedades ocidentais, a desaparecimento dos casamentos arranjados onde os pais escolhiam o cônjuge para seus filhos pode fazer acreditar no triunfo da livre escolha do cônjuge. Nós veremos que a realidade, todavia, é mais complicada (BORDAS, S/d, p. 70). 
O objetivo dos autores aparece claramente: trata-se de apresentar aos alunos os determinantes da escolha do cônjuge a fim de romper com suas ilusóes espontâneas do real. A recontextualização oscila entre uma objetivaçáo que repousa sobre a existência de soluçóes culturais diferentes na escolha do cônjuge e uma objetivaçáo que visa a introduzir a ideia de certas determinaçóes sociais. No primeiro caso, deixa-se supor certo arbitrário da solução no seio de uma multiplicidade de visóes culturais possíveis; no segundo, reexplora-se a ideia de causalidade, desenvolvida pelas outras ciências, que pode tomar a forma da reprodução social ou de estratégias dos atores.

\section{Os livros didáticos de CES: entre educação científica e educação do cidadão}

O exemplo da escolha do cônjuge nos permite observar o problema da recontextualização da sociologia nos livros didáticos de CES: como produzir um corpus de saberes acessíveis para jovens de 15 anos? Para responder a essa questão, os especialistas da didática estabeleceram, notadamente, os conceitos de transposição didática e de desintetização dos saberes (JOSHUA; DUPIN, 1993; CHEVALLARD, 1985).

A história do ensino das CES mostra que a inserção da sociologia foi pensada sobre o modo de distinção entre o saber universitário e o saber escolar. Os diferentes atores institucionais ${ }^{19}$ encarregados de constituir o curriculum formal reivindicaram muito cedo a ausência de concorrência entre o ensino da sociologia em CES e o ensino de sociologia na universidade. A ambição pluridisciplinar das CES se traduz, no curriculum, por uma transposição didática dos saberes de referência. O conhecimento sociológico é recontextualizado segundo um processo de "recriaçáo" do saber acadêmico em saber escolar e de recomposição, considerando as disciplinas julgadas próximas (antropologia, história, literatura etc. ${ }^{20}$. Quaisquer que sejam as razóes pedagógicas

19 Os atores institucionais, que determinam a escolha dos conhecimentos econômicos e sociais ao ensino, são múltiplos. Os órgãos oficiais do Ministério da Educação Nacional (comissão, grupos disciplinares, corpo de inspeção) criam os programas e as instruções. Acrescente-se a isso, a influência de cientistas para criar o que existe. Chevallard chama "a noosfera" que produz os saberes considerados "ensináveis", saberes que serão transpostos aos professores. Por seu lado, o corpo professoral e sua associação profissional (L'APSES) exerceram, desde o início, um papel determinante na definição do curriculum real.

20 Essas questões didáticas foram desenvolvidas por Y. Alpe em uma tese consagrada às CES, intitulada: Sociologie d'une innovation pédagogique: l'enseignement des sciences économiques et sociales au lycée. Thèse de doctorat, Université de Provence. Ver Alpe, 1995. 
avançadas para justificar essa transposição, as CES criam, finalmente, um quadro disciplinar específico que náo tem nada em comum com as disciplinas universitárias.

O caráter híbrido dos livros didáticos, que nós sublinhamos precedentemente, é, sem dúvida, ligado a essa transposição didática. A tomada de partido pluridisciplinar dos livros de CES dá lugar àquilo que os especialistas da didática chamam de "desintetização" do conhecimento sociológico. Um livro didático não pode, de uma maneira geral, assimilar a globalidade e a complexidade do conhecimento científico. Isso é mais verdadeiro nas ciências sociais, onde jamais houve reconstituiçáo de teorias gerais de conjunto. Por conseguinte, as teorias e os modelos científicos são dissociados em conceitos e em resultados cuja independência confere um caráter aporético ao saber escolar. Nesse caso da recontextualização da sociologia, essa "desintetizaçáo" acompanha uma despersonalização e uma dessincretização do saber acadêmico (JOSHUA; DUPIN, 1993). Trata-se lado a lado, da proibição do incesto, da escolha do cônjuge, da crise econômica etc. A "mise en textes" do saber acadêmico oculta o universo epistemológico e a lógica da démarche do sociólogo. Assim, os conceitos avançados não são construídos. Eles são colocados de modo ex abrupto e justapostos às noções que não têm o mesmo estatuto epistemológico. Isto é particularmente revelado no debate entre os professores de CES em torno de duas démarches antagônicas: o indutivismo e o dedutivismo. Digamos, rapidamente, que o indutivismo parte do conhecimento a priori dos alunos para construir as noçóes. Nessa perspectiva, os alunos têm, de algum modo, uma palavra a dizer, abrindo a via a uma possível apropriação, mas, também, a uma transfiguraçáo dos saberes. Por seu lado, o dedutivismo não tem completamente os meios de sua ambiçáo, visto que não pode definir senáo conceitos, sem realmente estabelecer sua organizaçáo, o que coloca fatalmente o problema da relação ou da concorrência entre as duas ciências sociais diferentes. A incomensurabilidade dos saberes sociológicos - não sendo sublinhada nos livros didáticos - e a escolha dos textos tomam, então, forma de um arbitrário que tem, por fio condutor, apenas a ilustraçáo de certa objetividade dos fatos sociais referenciada a uma normatividade externa à sociologia.

\section{Considerações finais}

A recontextualização da sociologia não é somente um problema pedagógico relativo à relação entre ciências sociais e saberes escolares. É, também, o 
problema da relação entre os conteúdos do ensino e a sociedade. A aprendizagem da démarche sociológica seria indissociável da ambição cívica das CES. A gênese da disciplina testemunha a vontade dos atores institucionais de colocar ênfase na educaçáo cívica no sentido amplo do termo. Nos livros, a sociologia é ensejada como um vetor de uma ideologia humanista. O social se confunde com o sociológico em um espaço relativista suposto a fim de desenvolver o espírito crítico e a abertura do espírito dos alunos. Essa perspectiva traçada por E. Durkheim nos seus escritos sobre a Educação (1966), não evita o risco do sincretismo. A linguagem natural e os conceitos sociológicos são convidados ao mesmo "banquete republicano" sem nenhuma distinção entre a lógica da ação e a lógica científica. Essas duas lógicas não se confundem, mas se confrontam. Reiteramos aqui o postulado positivista segundo o qual "é necessário conhecer para agir”. Isso dito, as categorias científicas são tomadas como fundamentos da ação, enquanto esta poderia se ancorar nos valores e nos direitos fundamentais (RAMOGNINO, 1992).

Podemos compreender a estratégia dos autores dos livros didáticos que são confrontados com o conjunto desses problemas, ainda mais pelo fato de o curriculum formal insistir sobre a sacrossanta liberdade do professor de CES:

Este ensino [...] repousa sobre a pedagogia ativa, e deixa aos professores o cuidado de organizar livremente seu trabalho no quadro do programa cuja coerência e equilíbrio devem ser respeitados. Em função de sua série, o professor identificará o programa dos objetivos de conteúdo e de método que fixará prioritariamente a seus alunos (Bulletin Oficiel du 24 de septembre de 1992).

O livro didático deve, portanto, seguir "a coerência e o equilíbrio" do programa deixando, ao mesmo tempo, uma margem de liberdade importante aos professores. Por conseguinte, a fórmula manual, é mais caleidoscópica que teórica. Esses constrangimentos curriculares não justificam, porém, tudo. Os livros de CES refletem, sobretudo, certa concepção da sociologia, própria a certos professores de CES para quem a explicaçáa dos fenômenos sociais, no âmbito do ensino no Ensino Médio, repousa necessariamente sobre as ilustrações, exemplificações, da literatura. A sociologia não poderia, assim, pretender às tentativas de formalização da economia. Nas suas perspectivas da sociologia, os autores dos livros didáticos parecem tratar sobre o mesmo plano, ou seja, sobre a ficção e o conhecimento sociológico, como se essas formas 
de conhecimento fossem alternativas. Por conseguinte, os livros de CES se apresentam como ferramentas de recontextualização de saberes "acadêmicos" oriundos da literatura sociológica.

\section{Referências}

ALPE, Y. Sociologie d'une innovation pédagogique: l'enseignement des sciences économiques et sociales au lycée. Thèse (Doctorat en sociologie) - Université de Provence, 1995.

BERNSTEIN, B. Basil Bernstein: La construction du discours pédagogique et les modalités de sa pratique. Critiques sociales, Ivry-sur-Seine, n. 3-4, p. 20-58, 1996 a.

Pedagogy, symbolic control and identity. London: Taylor and Francis, 1996b.

BERNSTEIN, B. L'enseignement de la sociologie: vers une étude comparative des curricula européens, Thèse (Doctorat en sociologie). Université de Provence. 1999.

BERTHELOT, J.-M. Les vertus de l'incertitude. Paris: PUF, 1996.

BOURDIEU, P. ; CHAMBOREDON, J.-C ; PASSERON, J.-C. Le métie de sociologue. Paris: Mouton-Bordas, 1968.

CHARLOT, B. Du rapport au savoir. Éléments pour une théorie. Paris: Anthropos, 1997.

CHEVALLARD, Y. La transposition didactique. Grenoble: La Pensée Sauvage, 1985.

DURKHEIM, É. L'évolution pédagogique en France. Paris: PUF, 1938.

Education et sociologie. Paris: PUF, 1966.

FORQUIN, J.-C. École et Culture. Bruxelles: De Boeck Université, 1989.

Les sociologues de l'éducation américains et britanniques. Bruxelles-Paris: De BoeckINRP, 1997.

ISAMBERT-JAMATI, V. Les savoirs scolaires. Paris: Ed. Universitaires, 1990.

JOSHUA, S.; DUPIN J.-J. Introduction à la didactique des sciences et des mathématiques. Pans: PUF, 1993.

RAMOGNINO, N. Le travail social a-t-il encore besoin des sciences sociales? Cahier de l'ADEUS, Marseille, n. 1, p. 93-122, 1992.

Normativité ou relativisme scientifique en sociologie? In : RAMOGNMO, N.; HOULE, H. (dir.), Sociologie et normativité scientifique. Toulouse: PUM, 1999. p. 179-207. Esta obra não foi citada explicitamente no texto. 
ROPÉ, F; BUCHETON, D.; LELOCH, N. Savoirs universitaires, savoirs scolaires, avec la collab. de D. Bucheton et N. Leloch. Paris: L'Harmattan, 1994.

VITALE, P. L’enseignement de la sociologie: vers une étude comparative des curricula européens. 1999. f. ? Thèse (Doctorat ?) - Université de Provence, 1999.

VITALE, P. The Teaching of Sociology: towards a European comparison of curricula. In: MORAIS, A. et al. Towards asociology of pedagogy: The contribution of Basil Bernstein to research. Berne: Peter Lang, 2001, S/p).

Recebido em: 10.07.2015

Aceito em: 20.10.2015

\section{Sociology face to the risks of economic and social sciences textbooks}

\section{Abstract}

Inspired by the Anglo-Saxon curriculum sociology, this paper attempts to highlight the recontextualization of sociology in french Economic and Social Sciences section, through the study of its handbooks. The analysis is confined on the whole of the secondary books and, in particular, on the chapters which deal with sociology. This examination lead, in fine, to release four forms of recontextualizations which invite to an epistemological, didactic and pedagogic reflexion, on the teaching of sociology in Economic and Social Sciences section.

Keywords: SES. Teaching of Sociology. Curriculum. Handbooks. Recontextualization. 